ISSN 1112-9867

\title{
FINITE ELEMENT INVESTIGATION OF THE PRESTRESSED JOINTED CONCRETE PAVEMENTS
}

\author{
M. Foroutan Naddafi ${ }^{1}$ and V. Sadeghi ${ }^{2, *}$ \\ ${ }^{1}$ Department of Engineering, Payame Nur University, Tehran, Iran \\ ${ }^{2}$ Babol University of Technology, Babol, Iran
}

Published online: 15 May 2016

\begin{abstract}
Precast prestressed concrete pavement (PCP) technology is of recent origin, and the information on PCP performance is not available in literature. This research presents a finite-element analysis of the potential benefits of prestressing on the jointed concrete pavements (JCP). With using a 3dimensional (3D) Finite-element modeling (FEM) the load transfer efficiency (LTE) of the prestressed pavement had been discussed. Longitudinal and transverse prestressing with various prestressing forces were analyzed. It was concluded that prestressing although increased the deflection at mid slab but the reduction in load transfer to adjacent is minor and engineers can benefit from the prestressing to reduce the slab thickness. The higher prestressing force, might affect the load transfer in the prestressed pavement, so using a prestressing for more than $400 \mathrm{kN}$ should be revised carefully.
\end{abstract}

Keywords: Prestressed concrete pavement; Dowel bar; Finite element; Load transfer efficiency.

Author Correspondence, e-mail: authorC@gmail.com

doi: http://dx.doi.org/10.4314/jfas.v8i3s.174 


\section{INTRODUCTION}

Prestressing is the application of a predetermined force to a concrete member so that the combination of internal stresses within the member, from this force and any other external loads, will be confined within specific limits[1]. Prestressed concrete pavements were used for airport pavement since 1940. Most of the early European airport projects used prestressing in both directions within the pavement [2]. Although prestressed technologies were used frequently in bridge deck and girders, but the first highway applications were in France in 1945, and in the United Stated was in military airfields in 1953[3]. Pre-compressing concrete slabs lead to a more efficient, thinner pavement resulting to material savings and improved long-term durability[4]. Other advantages are such as the ability to span voids that develop underneath the pavement because of many reasons.

The early projects mentioned were an early effort to improve and develop prestressed pavement. All of the early projects showed transverse cracking immediately after placement and longitudinal cracking few years later. Dowel bars at transverse joints in the concrete pavements are essential to transfer the loads applied on a slab to an adjacent slab. It also prevents faulting and pumping in JCPs $[5,6]$.

Recent progresses in software programing made it simple to utilize powerful finite element analysis software packages. The use of FEM in the analysis of rigid pavement dated back to the early 1960s with Cheung and Zeinkiewics use of the method to analyze slabs on elastic foundation[7]. Now, there are FE software packages able to predict pavements under various loading regimes.

In this study, a 3D FE model was established to assess a dowel-jointed prestressed concrete pavement. Three-Dimensional Finite-Element modeling (3D-FEM) has been broadly investigated to study the dowel bars at joints in rigid pavements [8,9]. Shoukri developed a 3DFEM to investigate the effect of moving axle loads on the response of dowel Jointed Portland Cement Concrete Pavement. He also showed that stresses increase under corner loading [10].

Recognizing the importance of knowledge gained by existing rigid pavement design, the objective of this study, is to assess the load transfer efficiency (LTE) of the dowels under static loads. It is known that prestressing reduces tensile stresses in the slab, so investigation of the stresses with the pavement is not an objective of this study. 


\section{MODEL DESCRIPTION}

A two-slab system with a 10-mm joint width on top of supporting layers was modeled by ABAQUS software package with using the Solid 3D elements to model the concrete pavement. The model geometry is identical to the model presented by Shoukry et al[11]. The transverse joint had twelve $32 \mathrm{~mm}$ diameter, $470 \mathrm{~mm}$ long dowels, spaced at $300 \mathrm{~mm}$ on center. Frictional contact stress is considered between the slab and base layer. A linear elastic constitutive model was used for the concrete slab and the underneath layers with the $254 \mathrm{~mm}$ thick slabs were 4600 $\mathrm{mm}$ long and $3660 \mathrm{~mm}$ wide, a modulus of elasticity, $E=29000 \mathrm{MPa}$ a Poisson's ratio, $v$ of 0.22 and a density of $2400 \mathrm{~kg} / \mathrm{m}^{3}$. A refined mesh zone as illustrated in Fig. 1 was located at the center of the joint, where wheel loads are applied. A base layer of $200 \mathrm{~mm}$ thick $(\mathrm{E}=310 \mathrm{MPa}$ and $v=0.3$ ) was modelled on top of the subgrade with $E=30 \mathrm{MPa}$ and $v=0.45$. A bonded interface action was considered between subgrade and base. Tendon with a modul elastisity of $190 \mathrm{GPa}$ and $1.4 \mathrm{~cm}^{2}$ section area was used in the model.

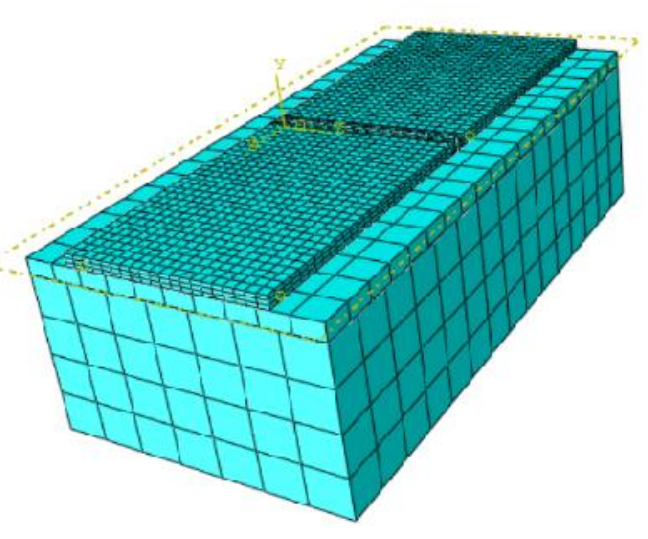

Fig.1. Finite-element mesh used for modelling 


\section{MODEL LOADING}

Repeated loads were applied to assess pavement deflections and observe the linear-elastic response of the pavement under repetitive loads of $20 \mathrm{kN}, 40 \mathrm{kN}, 80 \mathrm{kN}$, and $120 \mathrm{kN}$. Loads were applied at mid slab and edge as shown in Fig 2. The loading protocol was also suggested by Alwahediah [12].
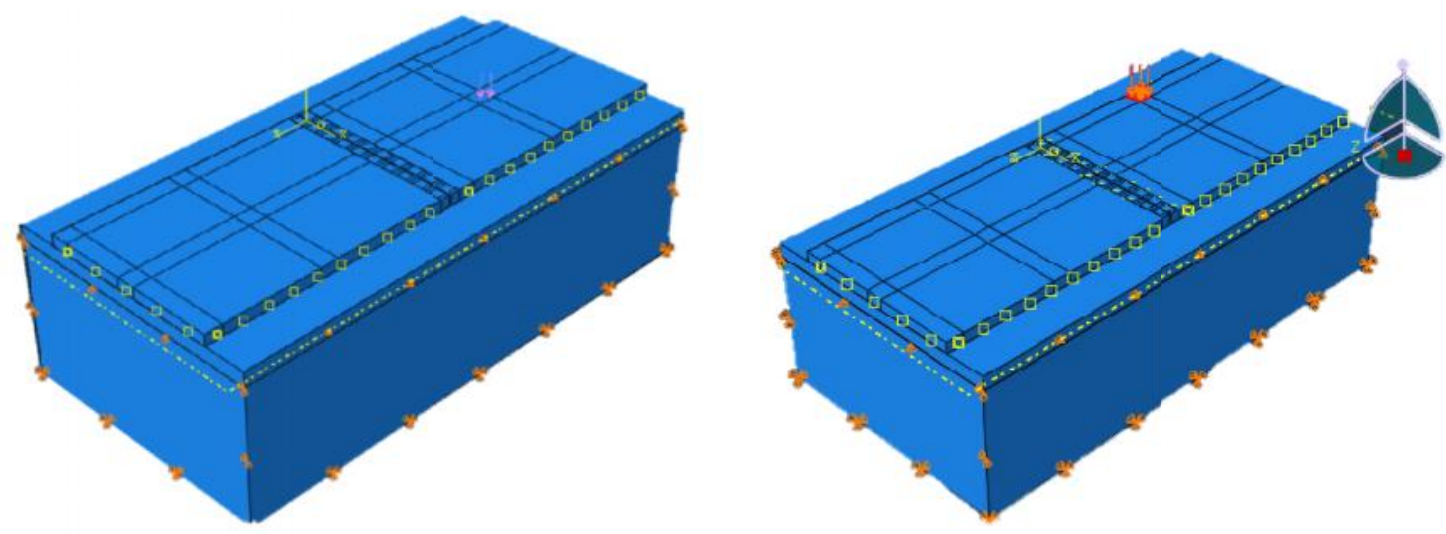

Fig.2. Loading location

\section{MODEL RESULTS}

The load transfer efficiency is defined by Eq. 1:

$L T E=\frac{\Delta_{u}}{\Delta_{l}}$

Where $\Delta_{u}$ and $\Delta_{i}$ are deflection of the unloaded and loaded side of the slab.

Fig. 3a shows the LTE calculated from the model with mid slab loading. In this phase, no prestressing is applied. Fig $3 \mathrm{~b}$ shows the maximum deflection of the center of the first slab. The lowest LTE is 0.8 for this situation. 


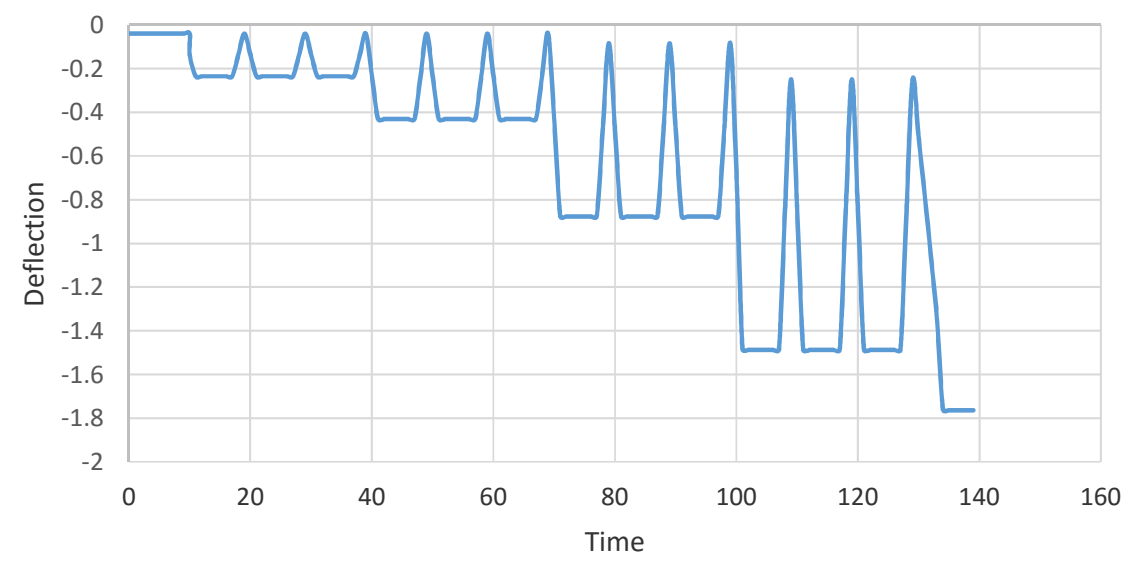

Fig.3.a. LTE Vs time when the load is applied on mid slab with no prestreesing



Fig.3.b. Deflection Vs time when the load is applied on mid slab with no prestressing

Fig. 4 shows the results of the loading on the mid slab when prestressing is applied on both transverse and longitudinal directions. The prestressing force is assumed to be $600 \mathrm{kN}$ for the both direction. The max deflection at the center of the slab was $3.5 \mathrm{~cm}$ which is high and caused by high prestressing force. 




Fig.4. LTE Vs time when the load is applied on mid slab with $600 \mathrm{kN}$ prestressing force on both directions

From Fig. 4 it can also be concluded that high prestressing force also has some impacts on the LTE. The maximum difference between the deflection of two edges was $5 \mathrm{~cm}$, which is higher compared to non-prestressed pavement where the maximum difference was $1 \mathrm{~cm}$.

Fig. 5 shows a slab with a similar prestressing ( $600 \mathrm{kN}$ on both directions), but the loading is implied one the edge of the pavement. This type of loading affected the LTE, as it is clear in Fig. 5.

In Fig. 6, the transverse prestressing is removed. The maximum deflection is reduced compared to previous case but the ratios of the deflection of the two slabs are a bit higher. Removing transverse prestressing had some effects on load transfer, when the edge loading is implied. 




Fig.5. LTE Vs time when the load is applied on the edge with $600 \mathrm{kN}$ prestressing force on both directions.

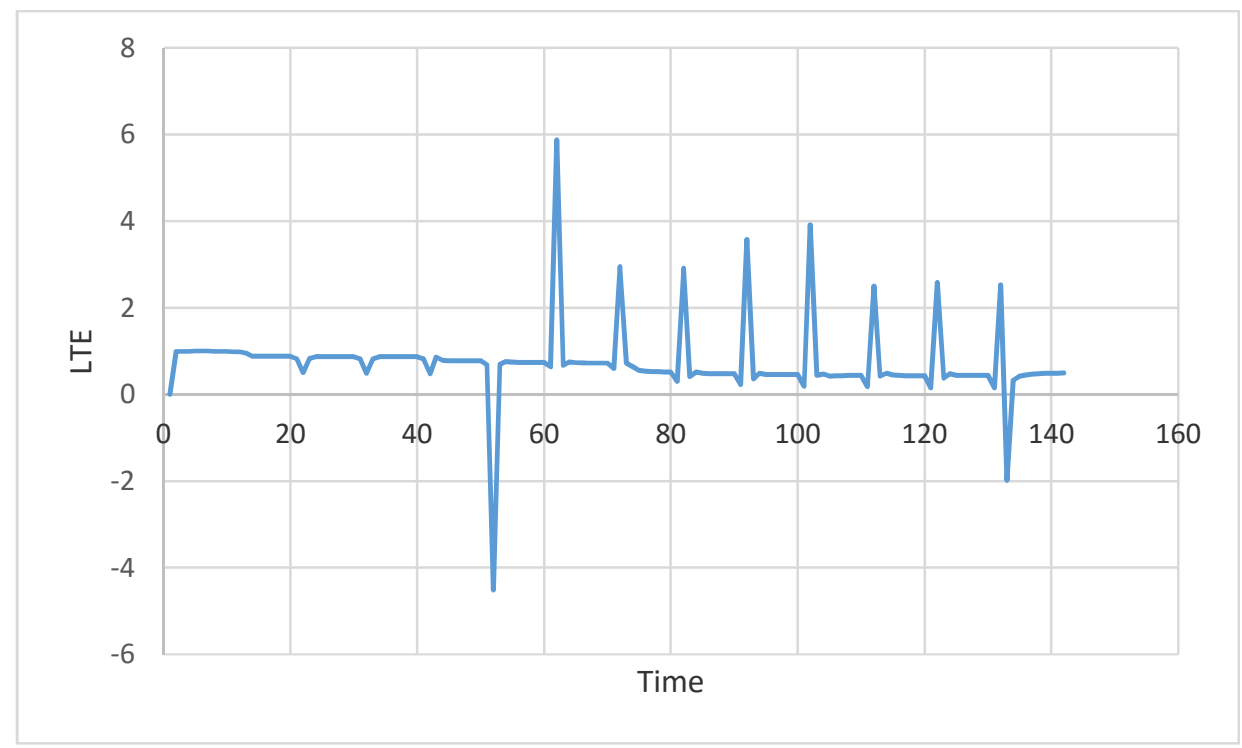

Fig.6. LTE Vs time when the load is applied on the edge with $600 \mathrm{kN}$ prestressing force on longitudinal direction

When the load is implied on mid slab the difference between the deflections of the slabs is ignorable as it is shown in Fig. 7 where only longitudinal prestressing is implied, but the loading is on the mid slab. The location of the load had a clear effect on load transfer between the two slabs. The mid slab deflection is as high as $6 \mathrm{~cm}$. 


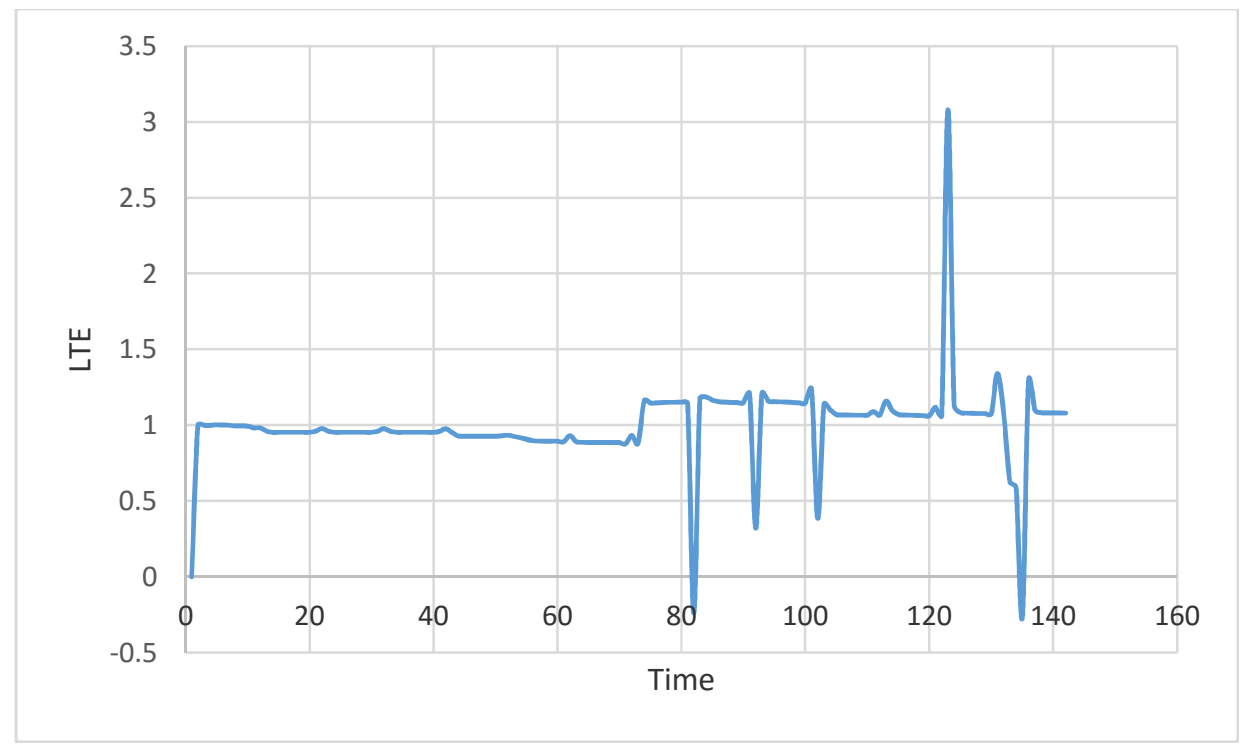

Fig.7. LTE Vs time when the load is applied on the mid slab with $600 \mathrm{kN}$ prestressing force on longitudinal direction

The $600 \mathrm{kN}$ prestressing force is a high prestressing force and might cause slabs move considerably against each other and it is not recommended to use such high prestressing force. Fig. 8 shows a case where prestressing is implied on both directions but with $400 \mathrm{kN}$ force. The result showed that the load transfer between the two slabs is reasonable and the maximum deflection of the slab is $4 \mathrm{~cm} .400 \mathrm{kN}$ prestressing for the both direction. Compared to the higher prestressing force, for the edge loading in this case load transfer performs better. Fig. 9 shows the edge loading for the latter case. Edge loading is more critical than any other type of loading during the life of the pavement and this detrimental effect can be seen in the load transfer between the slabs. 


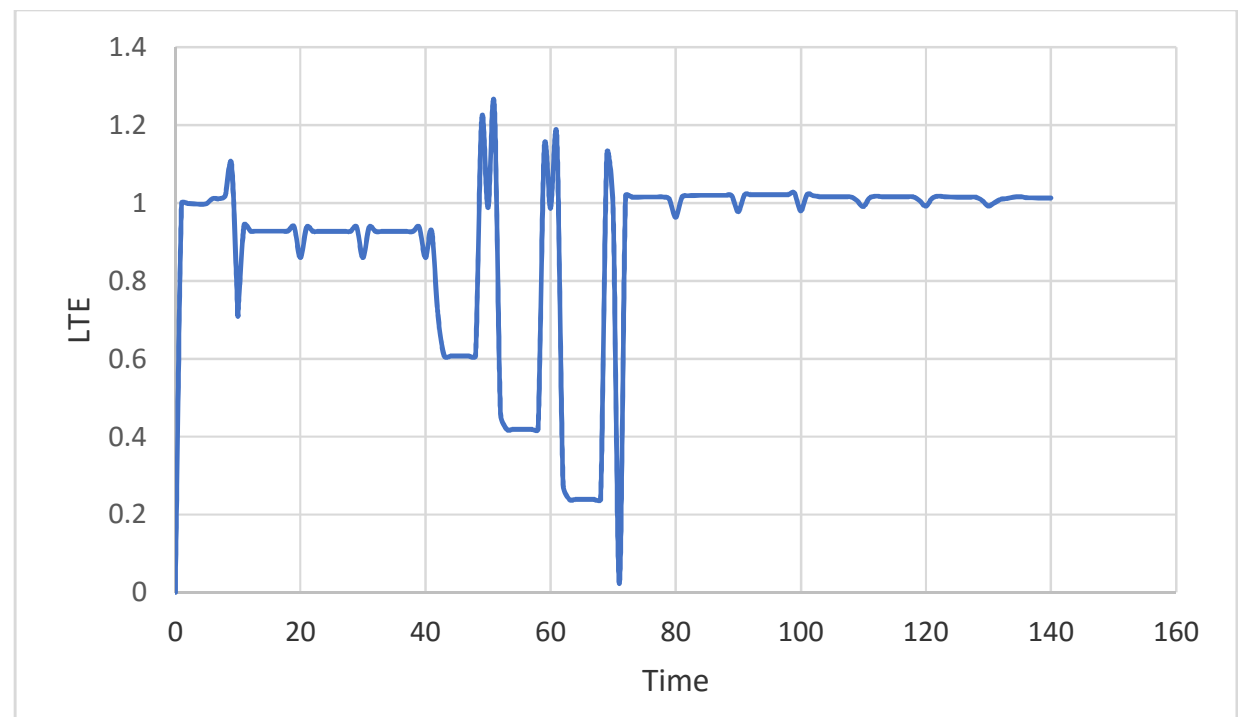

Fig.8. LTE Vs time when the load is applied on mid slab with $400 \mathrm{kN}$ prestressing force on both directions

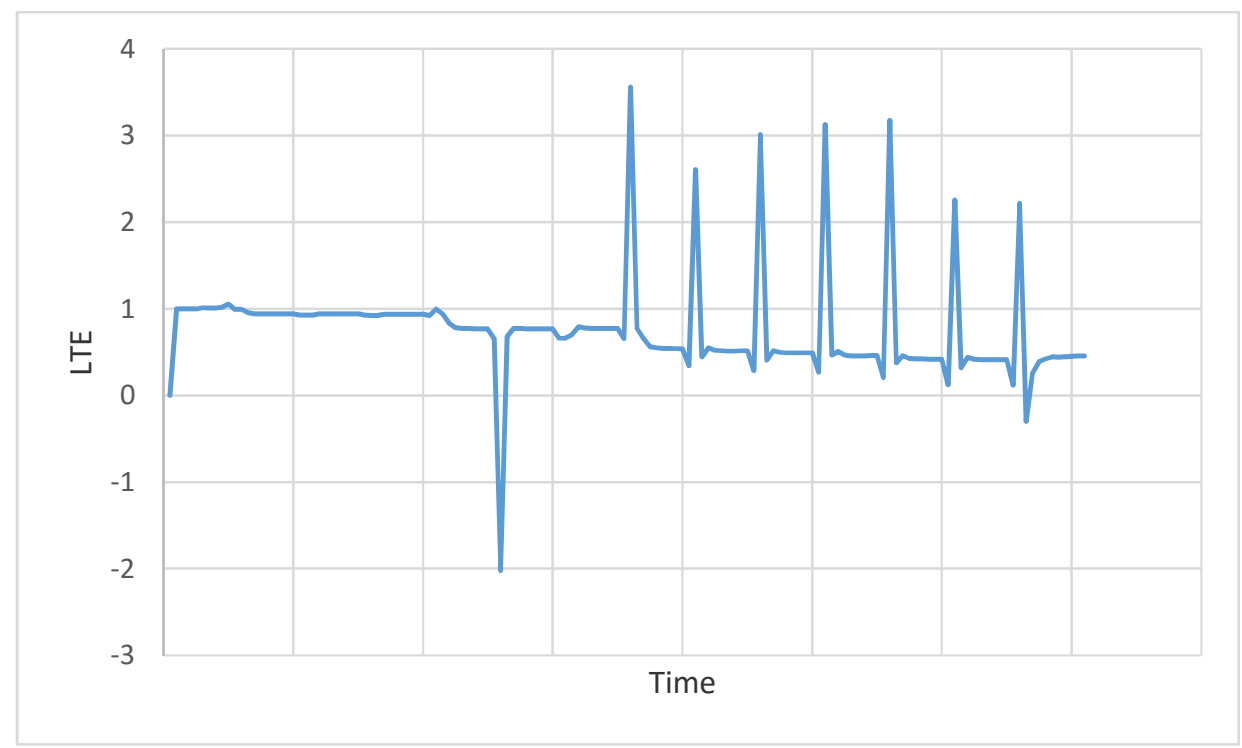

Fig.9. LTE Vs time when the load is applied on the edge with $400 \mathrm{kN}$ prestressing force on both directions 


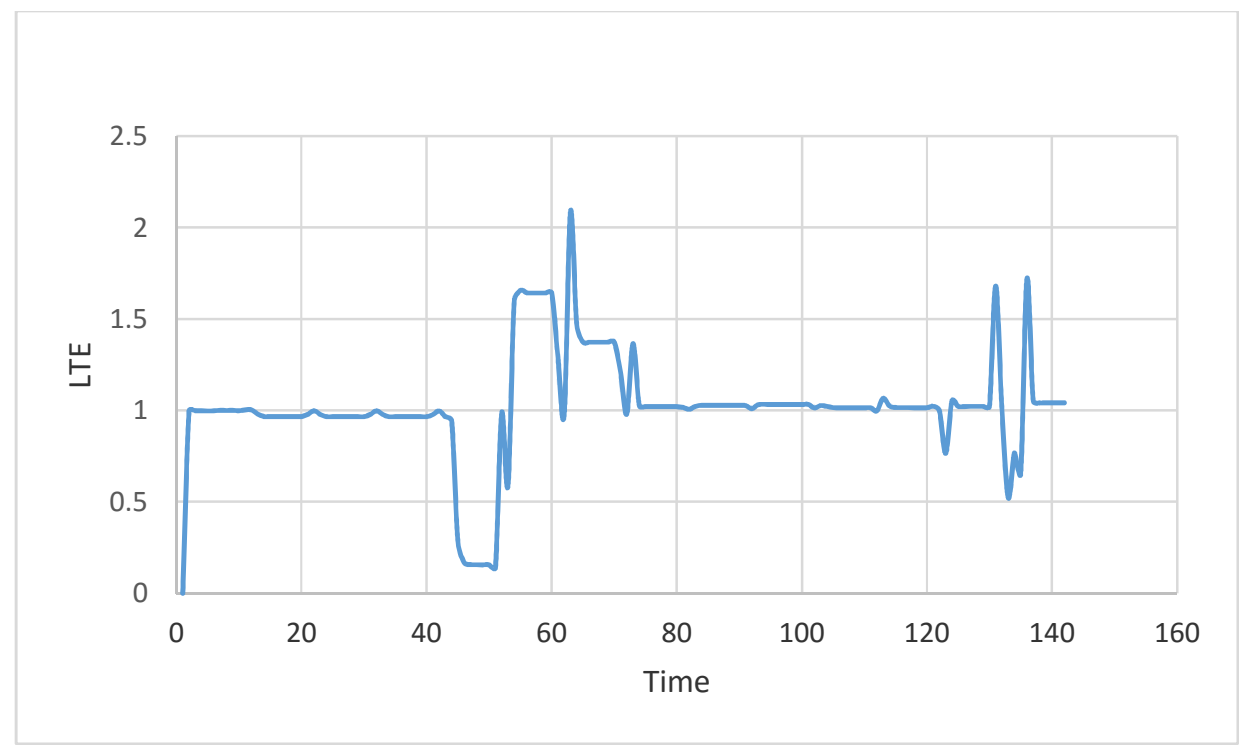

Fig.10. LTE Vs time when the load is applied on the mid slab with $400 \mathrm{kN}$ prestressing force on longitudinal direction

As said before, the edge loading is the most critical form of loading, and the load transfer is also vulnerable. When the pavement is prestressed these impacts are intensified. When prestressing force passes the $400 \mathrm{kN}$, the load transfer drops considerably.

\section{CONCLUSION}

This paper has examined effects of prestressing and loading on the load transfer efficiency of the prestressed pavement numerically. The study employed a FEM model developed with ABAQUS. Several models with utilizing two prestressing force, 400 and $600 \mathrm{kN}$, were developed to assess the impacts of prestressing and the loading location.

The results from the study have shown that the application of prestressing had a significant effect of the load transfer between adjacent slabs. It was shown that the $600 \mathrm{kN}$ prestressing force in both directions affected the load transfer and reduced it drastically. Edge loading is the most critical loading for the prestressed pavement and performs unpleasantly if combined with a high prestressing force.

The prestressing in both directions compared to single direction wasn't different and the benefits of the prestressing in the both directions can be used within the pavement considering the prestressing force. 


\section{REFERENCES}

[1] Libby JR (2012) Modern prestressed concrete: design principles and construction methods. Springer Science \& Business Media,

[2] Klunker F Status and Developments in the Construction of Prestressed Concrete Runways in European Airports. In: Proceedings of the 2nd International Conference on Concrete Pavement Design, held at Purdue University, April 14-16, 1981., 1981. vol Proceeding.

[3] Hanna AN, Nussbaum P, Arriyavat P, Tseng J, Friberg B (1976) Technological review of prestressed pavements.

[4] Luckenbill GC (2009) Evaluation of the service performance of an innovative precast prestressed concrete pavement. University of Missouri-Columbia,

[5] Cai H, Jiang K, Miao J, Liao JG (2012) Load Analysis of Transversely Prestressed Continuous Concrete Pavement with Oblique-Reinforced. Applied Mechanics and Materials 178:1179-1182

[6] Hachiya Y, Akamine F, Takahashi O, Miyaji Y Rapid repair with precast prestressed concrete slab pavements using compression joint system. In: Seventh International Conference on Concrete Pavements. The Use of Concrete in Developing Long-Lasting Pavement Solutions for the 21st Century., 2001.

[7] Huang Yang H (1993) Pavement analysis and design. University of Kentucky Prentice Hall, inc USA

[8] Levy C (2010) Numerical Investigation of the Effects of Shrinkage and Thermal Loading on the Behaviour of Misaligned Dowels in Jointed Concrete Pavement. Master of Applied Science, Waterloo, Ontario, Canada,

[9] Hesami S, Sadeghi V (2015) Numerical Investigation of the Shape Memory Alloy Dowels in Jointed Concrete Pavements. International Journal of Pavement Research and Technology 8 (4):251

[10] Shoukry S, William G, Srinivasan S (2002) Analysis of mid-slab transverse cracking in jointed concrete pavements. International journal of pavements 1 (3)

[11] Shoukry SN, William G, Riad M (2002) Characteristics of concrete contact stresses in doweled transverse joints. International Journal of Pavement Engineering 3 (2):117-129 
[12] Alwehaidah N (2013) Development of precast, prestressed concrete pavement technology. Oklahoma State University.

How to cite this article:

Foroutan Naddafi $\mathrm{M}$ and Sadeghi V. Finite element investigation of the prestressed jointed concrete pavements. J. Fundam. Appl. Sci., 2016, 8(3S), 167-178. 